\title{
RELATIVISMO NA AVALIAÇÃO DE EXECUÇÕES MUSICAIS
}

António Lopes

Centro de Filosofia da Universidade de Lisboa

Um facto interessante a notar na literatura de estética filosófica, e em particular na mais recente, é que, sendo o tema da avaliação da arte, dos princípios gerais que permitem discernir entre patamares de qualidade artística, um dos temas mais centrais a esse domínio filosófico, e provavelmente aquele cujo impacto prático é maior, a sua discussão ocupa um lugar desproporcionalmente pequeno. Com efeito, poderíamos resumir a situação do seguinte modo: por um lado, temos, de entre as teorias que mantêm a actualidade, ${ }^{1}$ um pequeníssimo número de propostas, umas mais sistemáticas que outras, de encarar de frente o problema, avançando critérios, com um grau aceitável de generalidade, para a fundamentação da verdade, ou correcção, dos juízos críticos em arte - Hutcheson, Kant, Beardsley, Goodmann, para não sermos excessivamente económicos ${ }^{2}$; por outro, encontramos discussões dessas propostas, de carácter predominantemente crítico em relação a elas, só raramente as desenvolvendo ou aperfeiçoando.

A este facto não será alheio, é simples de constatar, um predomínio de posições do tipo céptico ou relativista em matéria de crítica de arte,

1 Em geral, aquelas que a perderam devem esse facto à sua dependência estrita de compromissos mais vastos, geralmente de teor metafísico (caso de Hegel ou Schopenhauer), ou (ou por vezes em adição a) implausibilidades graves que as sujeitam a contra-argumentos evidentes (caso de Platão ou Tolstoy). Da doutrina kantiana, por outro lado, parece ser possível, sem violência irremediável, extraír uma perspectiva sobre a generalidade dos juízos sobre o valor artístico, manejável de modo razoavelmente autónomo em relação aos restantes aspectos do seu pensamento, como evidenciado pelo neo-kantismo estético contemporâneo, de que Anthony Savile é o mais conhecido expoente.

2 Com um mínimo de flexibilidade conceptual, penso que é clara a facilidade de uma redução, ou pelo menos de uma recondução, das restantes teorias do valor artístico a uma, ou a uma combinação, das mencionadas (para além de ser igualmente clara a dívida de Beardsley para com Hutcheson, por exemplo). É claro que quem discordar poderá juntar alguns autores da sua preferência, mas provavelmente muito poucos, se desejar realmente evitar a redundância nos pontos essenciais.

Philosophica, 27, Lisboa, 2006, pp. 121-134 
muito em consonância com a velha máxima latina que desaconselha disputas acerca de gostos e cores. Dado um tal panorama, não será de estranhar que os filósofos da arte se ocupem preferencialmente com tópicos como a definição de arte, a ontologia das obras artísticas, a expressividade e o papel das emoções na arte, a existência e natureza de uma atitude ou de uma experiência estéticas, e com os problemas que emanam da especificidade de cada tipo particular de arte, como a interpretação e a ficcionalidade na literatura, a representação em pintura ou a relevância de conteúdos morais em teatro e cinema. Assim, a regra parece ser o evitar de incursões pelo tema do valor artístico, um núcleo duro aparentemente tão pouco promissor que parece só servir para ocasionais adendas às razões para o alegado falhanço das propostas disponíveis, e, frequentemente, para explicar que qualquer alternativa concebível esteja votada a destino semelhante.

Se assim é na Filosofia da Arte em geral, não seria lícito esperar algo de diferente no domínio da filosofia da música. Mas, apesar de as coisas parecerem não poder ser piores para o defensor da mais ténue e modesta variante de objectivismo na arte dos sons, elas podem de facto sê-lo, se, como é o caso presente, se elege, como campo de investigação, não o da avaliação das obras de arte musicais, onde a escassez das referidas doutrinas positivas espelha fielmente a situação geral, mas o da avaliação crítica de execuções musicais, onde o esquecimento por parte de filósofos, bem mais acentuado ainda do que no caso da avaliação de obras, contrasta, de um modo simultaneamente gritante e surpreendente, com a proliferação da investigação sobre o tema sob perspectivas descritivas, nomeadamente as da musicologia, nas suas várias vertentes, e da psicologia da música.

Uma das raríssimas incursões nesta matéria é protagonizada por Jerrold Levinson, que, no seu ensaio Evaluating Musical Performance, lança mais umas quantas achas para a pira funerária em que jazem as pretensões objectivistas em matéria de execução musical. Tomando como domínio da discussão a tradição musical clássica do Ocidente, envolvendo obras notadas sob a forma de partitura e destinadas a serem executadas segundo certas convenções historicamente determinadas, a sua tese central é a de que não é dito nada que possa ter pretensões à verdade mediante juízos do tipo ' $p$ é uma boa execução de $w$ ' se estes forem tomados simpliciter, i.e., sem qualificação ou referência a contextos de apreciação. Podemos isolar as premissas do seguinte modo:

1. $p$ pode ser avaliada de uma série de pontos de vista diferentes.

2. Os veredictos resultantes de avaliações de $p$ sob diferentes pontos de vista são, geralmente, diferentes. 
3. Esses vários pontos de vista são, enquanto perspectivas de avaliação de execuções, igualmente legítimos à luz das nossas práticas musicais (mesmo que um deles possa habitualmente ser tido como referência na ausência de especificação).

Daqui se segue que uma execução julgada boa quando encarada de um certo ponto de vista pode não o ser se considerada de outro, sendo ambos relevantes, e que os juízos do tipo indicado acima são, na verdade, fúteis. Levinson chama a esta posição relatividade da avaliação musical a perspectivas.

O meu propósito será o de escrutinar os argumentos que, no entender do autor, permitem estabelecer uma tal posição. Em particular, e dado que 1. e 2. são verdades factuais, embora triviais, procurarei mostrar que 3. é demasiado fraca para firmar um relativismo consequente, e que os argumentos a seu favor são, ou desadequados ou inconclusivos como argumentos para uma tal versão não trivial de relativismo, que seria a pretendida. Saliente-se que o meu objectivo é, aqui, puramente negativo. Sem querer de momento ensaiar a defesa directa de uma forma de objectivismo na avaliação das execuções musicais, pretendo apenas mostrar que pelo menos estes argumentos em favor da doutrina oposta não colhem, e que, em geral, o ataque é mal direccionado.

\section{I}

Comecemos por esclarecer o que se entende aqui por pontos de vista relevantes numa abordagem da qualidade de uma execução de uma obra musical. Levinson tem em mente diferenças de três níveis $\left.{ }^{3}: 1\right)$ diferenças quanto ao papel desempenhado pelo avaliador no contexto da actividade musical, ou seja, se se é o (ou um dos) executante(s), o compositor da obra, ou apenas ouvinte da mesma ('apenas' porque este papel está incluído nos dois primeiros); 2) diferenças relativas ao papel de 'mero' ouvinte, no tocante ao grau de familiaridade com uma obra específica e com os contextos histórico-musical, artístico e técnico das obras da categoria e estilo relevantes, bem como os da execução das mesmas ${ }^{4}$; 3 ) dife-

$3 \mathrm{O}$ modo de apresentação desses pontos de vista por Levinson limita-se a uma lista em que todas as variantes surgem como casos a par uns dos outros, e inclui ainda o "ponto de vista da própria obra", i.e., o critério da autenticidade. Penso que a arrumação nas duas categorias acima faz sentido e é económica, dado que o último ponto de vista não poderá ser aqui tratado, uma vez que qualquer abordagem útil do problema exigiria muito mais espaço do que aquele que lhe podemos dedicar aqui.

4 Trata-se de competências diferentes e independentes, como fica patente se compararmos a situação em que um musicólogo especializado no barroco italiano ouve pela primeira vez 
renças de objectivos e contextos práticos com os quais ou nos quais as execuções são apresentadas aos diferentes auditórios. Na realidade, é no segundo tipo de diferenças que incidem, em meu entender, os argumentos aparentemente mais fortes de Levinson. Resumidamente, o que é considerado, de modo legítimo, como boa execução do ponto de vista de uma primeira audição, ou de um ouvinte neófito no estilo, género ou na totalidade da música "erudita", pode ser avaliado, de modo identicamente legítimo, por um ouvinte experiente em todos esses planos, como meramente passável. Por essa razão, mas também porque me parece haver aí alguma falta de clareza acerca do que se está a discutir, abordarei primeiro a relatividade quanto a pontos de vista decorrentes dos papéis assumidos numa execução, e a relatividade quanto a objectivos e contextos, de modo a poder pô-las de parte e dedicar o espaço restante àquilo que me parece ser o essencial da argumentação.

Segundo Levinson, os intérpretes têm, no acto da execução, uma experiência que, embora distinta da dos ouvintes, é também, grosso modo, estética, desde que, sem danos para a integridade da obra, procurem intensificar, mediante esse acto, a sua experiência (da obra, pressuponho). Ele identifica casos como aqueles em que o executante procura uma identificação com o compositor, o que origina uma certa maneira de frasear, ou busca uma sensação de libertação na facilidade com que executa passagens particularmente rápidas e difíceis. Deste modo, uma execução pode ser, para o próprio, satisfatória, ao passo que o ouvinte permanece alheio a tal avaliação.

Mas, em primeiro lugar, em que sentido serão estas experiências genuinamente estéticas? É verdade que tais sensações surgem, ou mais prudentemente, podem surgir no decurso de uma execução, e que decorrem de exigências da obra que por vezes não se podem arrumar facilmente como puramente técnicas, havendo uma mistura com a componente artística. Daí a reclamar para elas o estatuto de experiência estética, num sentido central que tenha implicações directas na avaliação do respectivo objecto estético (a execução), vai, contudo, um grande passo. Tais experiências parecem ser do tipo genérico da experiência de superar airosamente uma dificuldade, ou da partilha de certas intenções e emoções (neste caso, com o compositor supostamente ausente, ou talvez com uma persona, um sujeito, abstracto e imaginado, dos gestos musicais presentes na obra e das emoções nela expressas ${ }^{5}$ ). Mas nenhum destes tipos parece

um recém-descoberto concerto de Vivaldi de entre as centenas que o compositor veneziano escreveu, com uma em que um ouvinte sem instrução musical, conhecimentos de história da música ou de técnica vocal escuta pela $20{ }^{a}$ vez a sua ária de ópera favorita (das três que figuram na sua gravação de um espectáculo de beneficência organizado por Pavarotti).

5 Para uma explicação e defesa do conceito de persona da obra musical, ver Cone (1989) e Levinson (1996b), p. 107 e ss. 
por si só garantir o carácter estético da experiência, como pode ser visto se pensarmos num contabilista manipulando habilmente, em condições adversas, uma declaração de IRS de modo a conseguir o mínimo de "prejuízo" global para um seu cliente fortemente acossado pela Inspecção Geral das Finanças, ou, para o caso da partilha de emoções e intenções, nos adeptos de um clube reunidos durante o jogo.

Em segundo lugar, mesmo que concedamos que experiências deste tipo possam ser estéticas num certo sentido muito lato, elas são certamente derivativas, num grau importante, relativamente àquela que usualmente tomamos como a experiência estética que tipicamente se procura na audição de música, a que os compositores têm em mente proporcionar quando compõem, e que os executantes, eles próprios, tentam veicular (diferente da que (só) eles próprios têm, mais semelhante à que teriam como ouvintes de uma gravação da sua própria execução). Por exemplo, a perspectiva de que a culinária é uma arte com analogias com as artes performativas, e de que proporciona experiências genuinamente estéticas, embora à primeira vista bizarra, colhe contudo alguns argumentos respeitáveis. Creio no entanto que cairíamos claramente em erro se reclamássemos que a componente estética estivesse na sensação de se ter acertado na quantidade exacta de pimenta numa situação culinária particularmente adversa e/ou pejada de subtilezas, por oposição à apreciação, concentrada e dotada de discernimento, do prato (ainda que se seja simultaneamente o chef e o gourmet da refeição). Em ambos os casos, há uma experiência-alvo, que pode servir de pretexto para várias experiências associadas de realização, identificação, etc., mas que de modo algum se confunde com elas.

O mesmo vale para o ponto de vista diferenciado do compositor que escuta a estreia de uma obra sua, eventualmente a única ocasião em que ela será executada. Levinson diz-nos que este preferirá, quase sempre, uma execução que "lance luz sobre o processo composicional" ou sobre a arquitectura formal da obra, ao passo que a preferência do ouvinte poderá ser outra. Quanto ao primeiro critério, parece-me duvidoso como critério estritamente estético de avaliação de execuções, por demasiado dependente da relação pessoal com a obra e pelo carácter extrínseco da pretensa propriedade (que tem um aroma excessivamente intencionalista ${ }^{6}$ ). Já em relação ao segundo, embora seja, de facto, um critério indisputavelmente estético, a propriedade que lhe corresponde não é, porém, mais valorizada pelo compositor do que por qualquer ouvinte informado. Com efeito, ela representa uma das mais-valias praticamente indisputáveis de uma execução musical. Mas a questão fundamental mantém-se: seja qual for a especificidade e natureza das experiências ou preferências de intérpretes e

${ }^{6}$ No sentido clássico desse adjectivo em filosofia da crítica, empregue por exemplo em Wimsat e Beardsley (1989) 
compositores como não-ouvintes, parece-me evidente que, no campo da avaliação, e a fortiori no da avaliação das execuções (não da técnica ou da obra em si), elas devem ceder lugar à do ('mero') ouvinte, para quem, afinal, a música é escrita e executada. ${ }^{7}$

Passemos ao terceiro tipo de diferenças supostamente conducentes a relatividade na avaliação de execuções musicais. Levinson sustenta que os diferentes objectivos que uma execução concreta pode servir legitimam diferentes pontos de vista de avaliação, o mesmo se passando com os variados contextos em que ela pode ter lugar. Por exemplo, dada uma certa similaridade entre uma passagem de uma obra de Haydn e uma de Wagner, e uma execução da primeira que realce esse facto, diferentes juízos de valor serão admitidos consoante esta se destine a servir de introdução à ópera de Wagner, a acompanhar uma conferência intitulada "Haydn: a Música do Futuro?" ou "Haydn: as Raízes Rococó", ou a integrar uma fonoteca como gravação única. De igual modo, defende, uma execução é legitimamente julgada de modos diferentes conforme figure como parte de um programa de concerto variado em autores e estilos, como execução de uma obra única preenchendo todo o concerto, ou como parte de um ciclo de concertos com a integral das obras do compositor dentro desse género musical. Estamos a falar, de novo, em opções interpretativas como as de sublinhar a continuidade ou a ruptura com o passado, com o estilo do próprio compositor nesse género, e de evidenciar os efeitos e pormenores da obra em detrimento da coesão formal e unidade orgânica, ou vice-versa. Opções deste tipo só podem ser tidas como boas ou más em função do objectivo desempenhado pela execução, e do contexto em que ela é escutada.

Comecemos por fazer aqui uma distinção. Das diversas opções interpretativas mencionadas, devemos isolar a última, à semelhança do que fizemos na discussão do ponto anterior. Trata-se de uma opção que está presente (ou pelo menos deveria estar) em toda e qualquer execução

\footnotetext{
${ }^{7}$ Note-se que não pretendo ignorar o facto de que muitas peças musicais foram e são ocasionalmente escritas, por assim dizer, "para colegas", i.e., para serem apreciadas, na prática, por outros compositores, dadas as exigências técnicas e estilísticas impostas pela sua correcta apreciação. Não devemos, contudo, confundir este facto sociológico com uma verdade conceptual. Ainda que suceda, contingentemente, que outros compositores tenham sido historicamente o "público-alvo" dessas composições especiais, isso só revela que, de novo contingentemente, colegas compositores tenham estado melhor colocados, nessas ocasiões particulares, para a apreciação completa das obras, não que qualquer outro ouvinte na posse dos mesmos conhecimentos não pudesse figurar nesse auditório ideal pelo simples facto de não exercer a actividade de composição.
} 
séria de uma obra digna de atenção, independentemente de contextos e objectivos. A avaliação do sucesso do intérprete no equilíbrio entre os dois critérios ou na opção por um como dominante deve ser, por esse mesmo motivo, igualmente independente.

Quanto ao grosso do argumento de Levinson, e pondo de parte alguns exageros, creio que padece de uma excessiva contextualização do acto de avaliação da qualidade das execuções. Não falo apenas dos evidentes parâmetros subjacentes (técnico-artísticos) em relação aos quais toda a gente concordaria que contam como necessários para uma boa execução a um nível mais básico, mas que Levinson parece esquecer. Refiro-me também ao facto de que, tanto quanto me é dado ver, se se está a pôr em causa que haja qualquer base para estabelecer uma hierarquia de pontos de vista sobre a execução no que toca à sua avaliação, há que ter em conta que, se todos eles podem parecer legítimos, a legitimidade é, no entanto, um critério demasiado fraco para o efeito. Se a perspectiva do estudante que vai assistir ao concerto de acompanhamento da conferência sobre o carácter revolucionário da obra de Haydn é legítima, isso não nos garante que o seu veredicto, suponhamos informado e dotado de discernimento, sobre a qualidade da execução, influenciado como está pelo facto de estar a ser guiado para uma suposta característica da música de Haydn, esteja ao nível do de um crítico profissional trazido para o concerto sem conhecimento do contexto. Com efeito, embora em situações usuais os críticos estejam evidentemente na posse de tal conhecimento, parece que, no caso bastante sui generis sob consideração, a sua ausência teria, pelo contrário, algo do carácter da imparcialidade ou neutralidade que igualmente caracterizam o crítico competente. Não creio que o facto de acompanhar uma dada conferência em vez de outra no sentido inverso deva contar a favor ou contra o veredicto de que uma dada escolha interpretativa (digamos, salientar certas propriedades que podem ser tomadas como premonitórias de estilos futuros) funciona em termos estritamente musicais, o que é diferente de funcionar como consecução do objectivo da conferência em que está integrada.

Assim, podemos résistir a esta espécie particular de relativização de avaliações a contextos por meio de uma estratégia simples. Tomem-se as execuções de que temos vindo a falar, com seus diferentes contextos e suas opções interpretativas divergentes, e considerem-se todas elas num plano puramente sonoro, por exemplo, como gravações da mesma obra ${ }^{8}$, competindo em pé de igualdade pelo estatuto de boa execução neste sentido comparativo. Creio que estaria assegurada uma perspectiva de plano superior, mais abstracta, em que as propriedades estéticas, e mesmo muitas das propriedades artísticas relevantes, podem ser cuidadosamente

${ }^{8}$ Que, per impossibile, não tivessem nem traíssem a sua data e origem. 
escrutinadas pelo crítico experiente. Proponho que, desta perspectiva englobante, ainda que artificial (uma vez que, na prática crítica, o contexto desempenha sempre algum papel na avaliação), os critérios que o crítico poria em funcionamento para a emissão do seu juízo de valor informado - aquele a que daríamos privilégio - seriam, no essencial, aqueles que contariam como adequados e relevantes (ainda que outros possam ser legítimos), se esse mesmo indivíduo estivesse presente, na sua capacidade de crítico, em todas as situações contextualmente distintas acima descritas.

Convém não confundir o que aqui digo com uma negação de que algumas avaliações são feitas com referência a certos parâmetros contextuais, desde que se leve em conta que a avaliação é assumida como limitada a esses parâmetros. Em concreto, é evidente que o crítico profissional que assiste a um concerto dado por uma orquestra de escola pode proferir um juízo do tipo "a execução da Eroica foi razoavelmente boa para uma orquestra de escola" (ou mesmo "para uma orquestra de escola com estudantes deste nível, com este número de ensaios, com este maestro", etc.). Mas isto não parece ter na realidade quaisquer consequências relativistas ${ }^{9}$, uma vez que o mesmo crítico poderia ser chamado a proferir um juízo com um nível de generalidade superior, no sentido usado no parágrafo anterior, e facilmente obteríamos dele o tipo de juízo cuja relevância Levinson contesta: "foi uma execução medíocre da Eroica simpliciter".

\section{III}

Abordemos agora o tipo de relatividade restante, aquele que diz respeito ao grau de familiaridade do ouvinte com a obra e/ou com a informação histórico-musicológica relevante. $\mathrm{O}$ argumento pode ser claramente compreendido se seguirmos apenas o exemplo central de Levinson. Considere-se o $1 .^{\circ}$ andamento da grande Sonata D. 960, a última de Schubert, e o parâmetro da agógica ${ }^{10}$. Para o indivíduo que o escuta pela primeira vez, um tempo moderado a aproximar-se do rápido será mais indicado (i.e., dará uma execução melhor), uma vez que não só permite uma melhor apreensão da estrutura formal do andamento, como provavelmente evita uma perda de concentração, mais ou menos natural para um tal indivíduo, se o tempo for mais lento. Já para o ouvinte experiente,

9 Antes pelo contrário, provavelmente. A circunscrição rigorosa dos contextos de avaliação, no sentido descrito, bem como a correcta indexação do juízo de valor às categorias artísticas operativas no caso, podem ser vistos como denotando objectividade na avaliação, ou pelo menos, na apreciação e caracterização de objectos estéticos. Cf. K. Walton (1989).

10 Corresponde à rapidez da sucessão dos eventos musicais, também se usando a palavra italiana tempo para evitar a ambiguidade de 'andamento rápido' (secção de uma peça/velocidade concreta escolhida para a sua execução). 
um tempo mais relaxado poderá ser considerado adequado, deixando apreciar todos os pormenores que o executante realça, ou tornando a execução mais expressiva, nostálgica e romântica, dado que um ouvinte deste tipo está já preparado para a audição de um andamento muito extenso, controla o encadeamento das secções, a função e o carácter expressivo de cada passagem, etc. Deste modo, uma interpretação "invulgar e elevada", nas palavras de Levinson, seria, deste ponto de vista, a melhor interpretação, ao passo que do ponto de vista anterior, tal veredicto recairia sobre a execução que melhor veicula os contornos formais e o desenrolar do andamento.

Podemos contestar esta linha de argumentação de dois modos. Um consiste em disputar casuisticamente as afirmações acima sobre a adequação necessária (ou quase) de cada qualidade da execução às exigências de cada tipo de ouvinte. Assim, podemos sugerir que, em pelo menos alguns casos, o ouvinte não-iniciado fique relativamente indiferente ao andamento, sobretudo ao carácter sublimemente nostálgico do seu famoso tema de abertura, precisamente em virtude da escolha de um tempo moderado/rápido que o poderia banalizar. É até bastante provável, pois o que a maior rapidez consegue em termos de projecção da arquitectura da obra (pelo simples facto de as secções se sucederem mais rapidamente) pode sacrificar um bem argumentavelmente maior para o próprio principiante, a saber, a pura beleza melódica dos temas principais, algo bem mais acessível e atraente a esse ouvinte do que propriedades do género formal, habitualmente mais prezadas, e, de resto, notadas, por ouvintes iniciados.

Com efeito, não é de modo algum estranho que aquele nosso ouvinte reaja positivamente a algumas idiossincrasias do intérprete no sentido de realçar características do primeiro tipo em detrimento das do segundo, ou, em geral, privilegiar pormenores e efeitos, ainda que evidentes, tirando deles o maior partido expressivo e procurando uma interpretação elevada, ainda que um seu carácter eventualmente invulgar ultrapasse as competências adjudicativas do neófito. Já do lado do especialista, uma olhada rápida aos escritos críticos sobre execuções desta obra não deixa grande margem para dúvidas: a lentidão, a indulgência na exploração de efeitos românticos, e sobretudo a falta de clareza na projecção da forma são quase invariavelmente apontadas como defeitos, e a naturalidade no fluir do discurso musical, o evitar da sobreposição do ego do intérprete à simplicidade aparente da música, e em geral a contenção e economia de meios são as marcas de uma interpretação madura e adequada. ${ }^{11}$

11 Note-se que não desejo endossar esta perspectiva como a correcta comparativamente à imediatamente anterior. Apenas procuro mostrar "como as coisas são", com o objectivo de contestar que elas sejam provavelmente do modo contrário neste ponto específico, como Levinson defende. 
Mas é claro que esta não é a via mais adequada de contestar a tese de Levinson, pois arrisco-me a ver uma defesa da relatividade substituída por um seu negativo, em que as características positivas se tornam defeitos e conversamente, transitando incólume o pendor relativista para a posição revista (embora isso não seja estritamente verdade, como pode ser visto se atentarmos no último ponto, em que há de facto um consenso razoável entre os críticos). Prefiro a segunda estratégia, reminiscente, de resto, daquilo que defendi atrás, e que passa por pôr em causa o nivelamento da relevância dos pontos de vista para a correcta avaliação da execução, defendendo em alternativa uma hierarquização dessa relevância. Sejam quais forem as propriedades que cada ouvinte detecta, subjectivamente, em cada execução, há claramente um nível mais informado, mais dotado de discernimento estético, de independência e distanciação, de capacidade de enquadramento nas categorias adequadas e de comparação com os exemplos relevantes, em referência ao qual o juízo emitido por indivíduos com um grau menor de qualquer uma desta competências ou conhecimentos é normalmente qualificado, ou mesmo corrigido ${ }^{12}$. Essa, sim, é a prática do mundo artístico ao longo das diversas artes.

Esta linha geral de argumentação não constitui propriamente uma novidade filosófica, mas sim um apelo, para o caso específico da avaliação de execuções musicais, à noção de crítico ideal ${ }^{13}$ de Hume no seu "Of the Standard of Taste". Interrogando-se sobre as razões da disparidade desde sempre evidenciada nos nossos juízos estéticos, Hume separa o problema do relativismo em duas fatias. Em relação a uma delas, podemos fazer alguma coisa, dado que grande parte desse desacordo se deve à ausência, na maioria dos indivíduos, das qualidades raras que são a marca do crítico competente: sentidos apurados, sensibilidade delicada desenvolvida pela prática e aperfeiçoada pela comparação, isenção de preconceitos. É o juízo deste que devemos ter em conta (não o do debutante, o do autor-juíz em causa própria ou o de outras variedades). E quando, como ocasionalmente sucede, a discórdia irrompe mesmo entre as falanges dos críticos competentes? Pois bem, essa é a outra fatia do problema, e ela é, reconhece Hume, basicamente intratável, pois envolve disposições individuais acerca das quais pouco podemos fazer. Ora, se repararmos bem, o plano em que Levinson pretende detectar a sua espécie de relatividade é precisamente o da fatia em que o próprio Hume reclama uma dose saudável de objectividade. Não me parece haver grande vantagem nem sucesso em tentar ser mais humeano do que Hume.

12 Este facto sugere fortemente a possibilidade de que, pelo menos até um certo nível, alguns juízos de valor sobre execuções musicais sejam de facto falsos, e tomados como tal pelo mundo artístico, mesmo que os seus agentes se considerem a si mesmos como relativistas em geral.

13 "True judge". 


\section{IV}

Chamo agora a atenção para uma ideia que influencia a posição de Levinson, e que é a diferença que este vê entre a natureza da avaliação de obras musicais e a de execuções dessas obras. Há aqui duas situações distintas que convém não confundir. Uma é a defesa de que os critérios específicos que empregamos na avaliação de obras musicais não são exactamente os mesmos que empregamos na avaliação de execuções dessas obras (embora alguns possam ser comuns), ponto em relação ao qual estou de acordo. ${ }^{14}$ Não é no entanto neste sentido que Levinson reclama a existência de uma assimetria entre obras e execuções, mas sim num outro sentido, o de que certas diferenças de natureza ontológica entre elas têm como efeito que a avaliação de execuções seja de algum modo mais vulnerável ao relativismo, ao passo que a de obras, por analogia talvez com outras artes não performativas, admite um maior grau de objectividade, sendo inclusivamente para ele lícito o apelo a qualquer coisa como o que aqui refiro como ouvinte ideal no caso de obras, mas não no de execuções. ${ }^{15}$ Quanto a isto, estou em desacordo tanto em relação à conclusão quanto aos argumentos apresentados por Levinson para a extrair.

Relativamente à conclusão por si própria, a perspectiva de que intérpretes são artistas no sentido pleno, e de que execuções/interpretações ${ }^{16}$, no nível artístico que estamos aqui a considerar, são obras de arte por direito próprio, tem sido defendida, a meu ver correctamente, entre outros, por Peter Kivy. ${ }^{17}$ E embora ele não dê o passo seguinte, creio que podemos afirmar que, se execuções são, a seu modo, obras de arte, a relatividade ou objectividade que afecta a crítica de arte (de obras de arte) em geral será grosso modo aquela que afectará a de execuções musicais.

De qualquer forma, e independentemente da aceitação da premissa acima, as razões avançadas por Levinson para uma suposta assimetria neste ponto são fracas ou mesmo falsas. Quanto às duas primeiras, a saber, a singularidade das obras face à multiplicidade das interpretações e o carácter temporalmente efémero destas, não nos parece que signifiquem qualquer

14 Escrevo em pormenor sobre este tópico, nomeadamente em defesa de que há valores específicos das execuções, em Musical Works and Performance Evaluation, disponível on-line no site da British Society of Aesthetics, Post-Graduate Journal of Aesthetics 2005.

15 Subjacente a esta posição estará, talvez, a ideia de que obras musicais estão a par de obras dessas outras formas de arte como sujeitos de direito dos juízos críticos, enquanto execuções só o são derivadamente.

16 Sobre a acepção de 'interpretação' como de um executante ("performative interpretation"), e independentemente de uma interpretação no sentido do crítico de arte, ver Levinson (1996a).

17 Cf. Kivy (1995), p. 122 e ss., 264/5. 
"deficiência" ontológica por parte das execuções que implique uma maior exposição ao relativismo. Porque haveria a mais longa permanência no tempo de uma entidade de garantir maior objectividade nos nossos juízos de valor sobre ela? As execuções duram o tempo que duram, e têm as propriedades estéticas que têm, e isso deve ser o suficiente para a respectiva avaliação crítica. Quanto à multiplicidade das execuções, trata-se obviamente de uma caracterização que é, ela sim, relativa: só dizemos que as execuções de uma mesma obra são múltiplas; encarada por si, de modo resguardado da falácia da divisão, cada execução é saudavelmente uma só, e é isso que devemos avaliar, em comparação com outras execuções, tal como comparamos obras de um mesmo género, estilo ou compositor.

Os dois restantes argumentos a favor de que a relatividade que afecta a avaliação de execuções é significativamente menor que a que afecta a de obras assentam em suposições falsas. Quanto ao primeiro, o suposto facto de as obras serem o objecto primordial de atenção em todas as execuções pode ser facilmente desmentido pelos inúmeros melómanos que acorrem ao teatro de ópera para ouvir o seu soprano ou tenor favorito a despeito da récita em causa ser de uma obra que lhes não agrada particularmente, bem como por qualquer professor de instrumento ou voz. ${ }^{18} \mathrm{E}$ relativamente a outro alegado facto, o de que a qualidade das obras musicais não está dependente do falhanço de alguém menos preparado em apreciá-las, não compreendo por que motivo poderá o valor de uma interpretação ser afectado pela falta de sensibilidade e do conhecimento relevante de um ou vários dos seus ouvintes contextualmente situados, e menos ainda que tal fenómeno intrigante afecte execuções de um modo tão drasticamente superior relativamente a obras musicais. Em termos de teorias do valor estético, ambas as entidades, obra e execução, encaixam perfeitamente como objectos estéticos na perspectiva prevalecente de que esse valor consiste na capacidade que o objecto tem para gerar experiências com determinadas características. ${ }^{19}$

$\mathrm{Na}$ verdade, penso que Levinson se trai um pouco quando admite o seguinte: "Se bem que pense que o ponto de vista do ouvinte experiente e informado é central, [...] dificilmente é a única posição de importância no contexto musical"20. Esta afirmação poderia perfeitamente ser generalizada à avaliação da arte em geral: há ganhos a tirar da experiência de objec-

18 Julgo ser evidente que a minha posição é a de argumentar contra a ideia de que a obra é sempre ou quase sempre o objecto primordial da atenção de ouvintes competentes, não a favor de que esse objecto seja sempre ou quase sempre outro (nem, claro está, que haja algo de mais ou menos correcto, nalgum sentido desta palavra, num ou noutro modo de audição).

19 Quais elas são, variará consoante a teoria. Mas o essencial é que execuções nada têm de constitutivamente impeditivo de que ocupem o papel de objectos estéticos nessas teorias.

20 P. 191 
tos estéticos (obras ou execuções) em todos os graus de familiaridade com eles, incluindo mesmo situações "esteticamente anómalas", mas nem por isso menos comuns, como apreciar as mais ricas, complexas e profundas pinturas ou composições como padrão para papel de parede ou como música de elevador, respectivamente. Mas é pacífico que o ponto de vista do crítico experiente e informado é, não meramente central no sentido fraco que Levinson emprega, mas decisivo, se alguma coisa o é (se o não for, a consequência mais grave seria trazer obra musical e interpretação para o mesmo nível, o que contradiria a ideia da assimetria obra/interpretação acima discutida).

Ora, em geral, uma tese relativista tem que argumentar cabalmente contra a existência ou legitimidade de uma perspectiva de nível superior, em qualquer dos sentidos relevantes da expressão. E é isso que Levinson não parece conseguir estabelecer, pois o mesmo mundo da música, cujas evidências invoca para dar substância ao seu perspectivismo, reconhece perspectivas mais elevadas e relevantes para a avaliação, tanto de obras musicais como de execuções das mesmas. $\mathrm{O}$ facto de que "algumas execuções servem melhor os ouvintes em determinado momento do que outras" 21 não exclui que haja um ponto de vista sobre elas que é idealmente imune precisamente ao critério relativizante "quem é melhor servido". Esse é o ponto de vista do crítico ideal de Hume e dos seus mais terrenos homólogos humanos, e essa a razão pela qual a eles recorremos.

\section{Referências}

Cone, Edward T. (1989) "Expressiveness in Music", in George Dickie (ed.) Aesthetics. A critical anthology, St. Martin's Press N.Y.

Hume, David (1989) "Of the Standard of Taste" in Dickie (ed.) Aesthetics. A critical anthology, St. Martin's Press N.Y.

Kivy, Peter (1995) Authenticities. Philosophical reflections on musical performance. Cornell

Levinson, Jerrold (1993) "Performative vs. Critical Interpretation in Music" in M. Krausz (ed.) The Interpretation of Music, OUP

(1996a) "Evaluating Musical Performance", in Music, Art and Metaphysics, Cornell.

(1996b) "Musical Expressiveness" in The Pleasures of Aesthetics, Cornell

Walton, Kendall (1989) "Categories of Art", in Dickie (ed.) Aesthetics. A critical anthology, St. Martin's Press N.Y.

Wimsat, William K. e Beardsley; Monroe C. (1989) "The Intentional Fallacy", in Dickie (ed.) Aesthetics. A critical anthology, St. Martin's Press N.Y. 


\begin{abstract}
As in other domains of art, the assessment of performances or interpretations of musical works is largely considered as a matter of personal taste. In Evaluating Musical Performance, Jerrold Levinson argues that relativism, in this matter, depends on the many interests with which a performance can be faced, and, consequently, evaluated and assessed. My thesis in this article is that not all interests have the same importance and that there is a "purely musical" perspective that must prevail over the other interests. This way I try to diminish the so called relativism.
\end{abstract}

